\title{
An exploratory study on knowledge sharing behaviors of university students in Singapore
}

\author{
Robert Jeyakumar Nathan*, Ibrahim Musah, Solarin Sakiru Adebola, Guru Dhillon
}

Faculty of Business and Law, Multimedia University, Jalan Ayer Keroh Lama, Bukit Beruang, 75450 Melaka, Malaysia

\section{A RT ICLE INFO}

\section{Article history:}

Received 8 December 2016

Received in revised form

8 April 2017

Accepted 8 April 2017

\section{Keywords:}

Knowledge sharing

Higher learning institutions in

Singapore

Varsity students

Competition in learning

Image of learning institutions

\begin{abstract}
A B S T R A C T
Knowledge sharing in an institution of learning process is important component for creativity and stimulation of intellectual discourses. Nonetheless, knowledge sharing requires the unification of students' effort, tenacity and willingness to go beyond their limits and engage with other. Hence, identifying the behavioural factors among students that influence knowledge sharing in institution of higher learning is important. This ongoing study reviews the current literature on knowledge sharing behaviour among students in Singapore. Students from institutions of higher learning in Singapore, private and public, were determined as sample of the study. A search of the literature was conducted across the Junior Colleges, Polytechnics, Nanyang Technological University (NTU), National University of Singapore (NUS) and Singapore Management University (SMU). The findings of the initial phases were presented in this report. Exploratory study was first carried out and Students and staffs from various institutions were interviewed to collect impotent information that sets the background for the study. To determine these factors, questionnaires were designed and distributed to the sample students to collect research data. Out of the 300 data collected, 217 samples were concluded for data analysis. The result shows that Singapore students were found generally sociable and open for knowledge sharing among peers. They show high level of trust when it comes to receiving information from their peers. Results reveal various other peculiar characteristics of students in Singapore and their knowledge sharing behaviour.
\end{abstract}

(C) 2017 The Authors. Published by IASE. This is an open access article under the CC BY-NC-ND license (http://creativecommons.org/licenses/by-nc-nd/4.0/).

\section{Introduction}

Gone are the days where tutors simply assign work to individuals. The increased emphasis on teamwork has, more often than not, been evidenced in the assessment criteria of schools through students' involvement in group projects. The discussions of learning organization come to mind, from components such as team learning and shared vision (Senge, 1990) to the constant cycles of conversions between tacit and explicit knowledge (Nonaka and Takeuchi, 1995). Rapid movements in technology helped in the above and have reshaped the way both educators and students approach learning as we see online research become a norm in a tertiary student's academic life (Crovitz and Smoot, 2009). The important role that knowledge sharing

\footnotetext{
* Corresponding Author.

Email Address: robert.jeyakumar@mmu.edu.my (R. J. Nathan) https://doi.org/10.21833/ijaas.2017.05.010

2313-626X/C) 2017 The Authors. Published by IASE.

This is an open access article under the CC BY-NC-ND license

(http://creativecommons.org/licenses/by-nc-nd/4.0/)
}

plays in organizational development is increasingly being recognized (Laycock, 2005; Behery, 2008). The issue here however, is whether the said institutions and students as part of a knowledge-intensive, educational environment - are equipped with the correct mentality and capabilities to allow active interactions, exchanges and sharing of knowledge.

Singapore due to its geographical features has no natural resources to speak of, when it comes to valuing herself against the competitive global markets. With a national education budget expenditure of 7.53 billion Singapore dollars, she prides herself on human capital with a strong focus on education to train her people to be knowledge workers as one step towards a knowledge-based economy (MOF, 2009). To implement and encourage successful and effective and efficient knowledge sharing is a challenging process.

\subsection{Personal attributes and knowledge sharing}

As knowledge sharing commonly occurs at face to face level amongst students, one should not 
disregard personality of individuals when it comes to such an exchange of knowledge. A high level of trust shown towards one another, possession of agreeable traits such as "kind", "sympathetic" and "modesty" can complement the processes of knowledge sharing, with the same said towards the inverse characteristics in hindering knowledge sharing (Mooradian et al., 2006).

Level of trust could also be associated with the credibility of the person; that the perception of people with, for example, expert and referent power, in the educational context, a professor and a student is seen as an achiever, are people that command credibility and therefore are sources for people to seek knowledge from (French and Raven, 2015; Politi, 2005). On a similar note, the strength of relational ties between the members in this educational setting, the sociability of students, would determine ease and the way knowledge is shared (Marouf, 2007).

\subsection{Incentives to share knowledge}

Many times, organizations have resorted to the use of monetary rewards as an incentive to encourage the sharing of knowledge. Working in disfavor is the fact that it is hard to reward, directly and explicitly, due to the intangibility, voluntary nature of knowledge sharing (Jarvenpaa and Staples, 2001; Grant, 1996; Lin, 2007). Having people with the personality and mindset would not be sufficient when the organization itself is not providing the means and platform to facilitate the sharing of knowledge.

In the study by Wolfe and Loraas (2008), it was stated that regardless of the form of rewards, the incentive must be sufficient; while they partially agreed with Lin that monetary incentives should not be the optimum choice of rewards, the unfortunate fact that non-monetary based incentives (such as recognition) are often hard to measure results to encourage knowledge sharing amongst people in the organization.

Moreover, given the efforts needed to implement and manage knowledge sharing, organizations do not see it as being in line with the generic "maximize profit, minimize cost" goals of most organizations and are therefore, unnecessary (Desouza and Raider, 2006). The implication here lies in the perception of schools as an organization and with money out of the equation, what would make students want to share knowledge?

\subsection{Quality of information, type of information and knowledge sharing}

In order to help them at home, in their society and communities and in their work life, students are in schools to teach (Dewey, 1938). The author argues that students do not possess the relevant knowledge and information prior to learning. It is thus difficult for students to share knowledge amongst other students that would help them through the requirements of study. Failure to evaluate information (Bloom, 1956) handed to them may result in undesirable outcomes, à la "garbage in, garbage out" such as low quality work (Fitzgerald, 2000). Likewise, not knowing enough hold back a student's willingness to share.

Essentially, the difference between information and knowledge would be that knowledge is a more organized thought with the element of experience (Bennet and Bennet, 2008). The authors went on to classify knowledge into surface, shallow and deep. Students are likely to possess and exchange more, and with ease - surface to shallow knowledge, e.g. study methods, sources of information, tips and memorizing to pass examinations. While it is possible to argue that shallow and surface knowledge might be all that is needed for students to get by their academic life, the usefulness of such knowledge outside of school diminishes as compared to deep knowledge.

\section{Literature survey}

While there has been a lot research done in profit-oriented organizations on knowledge sharing, little has been done with reference to the education sector, particularly knowledge sharing between students. An interesting study was carried out by Ting and Majid (2007) from Nanyang Technological University of Singapore. The study revealed positive attitudes of students towards knowledge sharing and identified competition and peer relation to be the main obstacles to successful knowledge sharing between students (Ting and Majid, 2007).

The educational scene in Singapore is changing, nonetheless, her practices of sorting students into different tracks, ranking schools with respective "cut-off" or entry points paint a picture of that of competition in education. Knowledge provides the competitive edge for students to be the best amongst peers, thus creating a knowledge sharing barrier due to knowledge hoarding (Davenport and Prusak, 1998; Senge, 1998; Ting and Majid, 2007).

This study seeks to investigate further into peer relations exploring the behavioral traits (or personality) of students, the systems in play of a student's environment and the type \& quality of knowledge sharing. The study also includes new variables and includes students from Junior Colleges, Polytechnics, Private Universities, Nanyang Technological University (NTU), National University of Singapore (NUS) and Singapore Management University (SMU). As this is an on-going research, the paper would also look at the eventual consideration and proposal of an online knowledge sharing system similar to that of Wikipedia in schools.

\subsection{Wikipedia and knowledge sharing}

Wikipedia positions itself as an online encyclopedia that anyone can edit, which presents a problem when it comes to credible information that is required of students in academic work. In its 
worst, educators dislike the idea as it represents lazy researching on the part of students due to the ease of accessing the information, yet on the other hand, it can also represent a real and dynamic approach to scholarly work (Crovitz and Smoot, 2009). Another research on Wikipedia revealed its content to be of "surprisingly high quality" and thus reliable as a source of information (Rahman, 2008).

The workings of Wikipedia - the discussions, constant revisions are reminiscent of that of Nonaka (1994) concept of the creation of knowledge through conversion tools like externalization and internalization, the difference is these exchanges are taking place online. With technologies that allow for synchronous communication and the ability to impart tacit knowledge in the form of one's own experiences online, it is possible to overlook the requirements of face-to-face interactions to create knowledge (Yi, 2006). Further supporting this comparison is the fact that like knowledge sharing, there are no incentives involved, and contributing to Wikipedia is strictly a voluntary affair.

\section{Methodology}

The target respondents of this study, apart from students from NTU, NUS and SMU, include institutions such as Singapore Institute of Management and University of Newcastle, Australia via PSB Academy Singapore, which offers private degrees; as well as students pursuing postsecondary education - from Junior Colleges to Polytechnics. The questionnaire handed out consisted of six sections, containing 53 mostly scalar questions requiring respondents to pick from a range of 1 to 6 .

The questions gather background information of respondents; investigates information sources of students, their personality traits when it comes to knowledge sharing, perception of their respective learning institutions and etc.

Table 1: Personal attributes and knowledge sharing

\begin{tabular}{|c|c|c|c|c|c|c|}
\hline \multirow{4}{*}{ I have confidence in the answers provided by my peers } & \multicolumn{6}{|c|}{ Tend to Disagree $\%<------------\rightarrow$ Tend to Agree \% } \\
\hline & SD & MD & $\mathrm{D}$ & A & MA & SA \\
\hline & 0.5 & 5.0 & 19.5 & 38.5 & 31.0 & 5.5 \\
\hline & \multicolumn{3}{|c|}{$25 \%$} & \multicolumn{3}{|c|}{$75 \%$} \\
\hline \multirow[t]{2}{*}{ I am a sociable person } & 2.0 & 5.0 & 14.5 & 34.5 & 26.0 & 18.0 \\
\hline & \multicolumn{3}{|c|}{$21.5 \%$} & \multicolumn{3}{|c|}{$\mathbf{7 8 . 5 \%}$} \\
\hline \multirow[t]{2}{*}{ I work well in groups } & 0.5 & 6.5 & 17.0 & 40.5 & 27.0 & 8.5 \\
\hline & \multicolumn{3}{|c|}{$24 \%$} & \multicolumn{3}{|c|}{$76 \%$} \\
\hline \multirow[t]{2}{*}{$\begin{array}{l}\text { I feel that I can complete most of the group-assigned } \\
\text { tasks alone }\end{array}$} & 2.5 & 8.5 & 27.5 & 32.0 & 17.0 & 12.5 \\
\hline & \multicolumn{3}{|c|}{$38.5 \%$} & \multicolumn{3}{|c|}{$61.5 \%$} \\
\hline \multirow[t]{2}{*}{ I am afraid of giving the wrong answers } & 4.0 & 8.5 & 17.0 & 20.5 & 35.5 & 14.5 \\
\hline & \multicolumn{3}{|c|}{$29.5 \%$} & \multicolumn{3}{|c|}{$\mathbf{7 0 . 5 \%}$} \\
\hline \multirow[t]{2}{*}{ I am afraid of people giving me the wrong answers } & 9.5 & 7.5 & 17.0 & 29.0 & 22.5 & 14.5 \\
\hline & \multicolumn{3}{|c|}{$34 \%$} & \multicolumn{3}{|c|}{$66 \%$} \\
\hline
\end{tabular}

\subsection{School as an organization}

Most of the time, schools do not emphasize monetary objectives when it comes to the provision of education, but rather on the holistic developments on students through the provision of high levels of education. From Table 2, students' perception of
The questionnaire was distributed through convenience sampling via two methods; online and hard copy. The online form allowed collection to be done without physically being present in the institute hence circumventing the fact that some of the institutes were having their examinations during the data collection. Students from various academic faculties participated in the study from the institutions mentioned above.

\section{Result and discussion}

The results of the study are discussed in the following subsections. As the study is still on-going, to this extent, only preliminary findings are presented.

\subsection{Personal attributes}

The respondents were made to answer on a scale of 1 to 6 i.e. Strongly Disagree (SD), Moderately Disagree (MD), Disagree (D), Agree (A), Moderately Agree (MA) and Strongly Agree (SA). The answers from 1 to 3 are treated on the side of "tend to disagree", likewise 4 to 6 on the side of "tend to agree".

From Table 1, majority of the students responded that they possess knowledge-sharing traits such as being sociable (78.5 per cent) and being group players (76.4 per cent) - but acknowledged that they can complete most of the group-assigned tasks alone.

It is worth pondering the motive of schools giving group tasks. Is the rationale of schools handing outgroup tasks as being symbolic (of knowledge sharing) or simply because the work that is required to be done is too much to complete alone? Curriculum need to be clear in setting out the objective of giving out group tasks, to emphasise the right motive to students. schools' focus on reputation and image is clear (87.2 per cent), however there is a lack of common understanding as students do liken schools to profitseeking organisations (67.9 per cent).

A less than significant percentage of 64 when it comes to whether students feel a sense of belonging and a sizeable portion of 38.6 per cent with regards 
to whether students know their schools' mission and vision indicate a less than desirable connection with regards to a student's alignment to the school as an organisation.

Table 2: Perception of the institution of learning

\begin{tabular}{|c|c|c|c|c|c|c|}
\hline \multirow{4}{*}{ I feel a sense of belonging to my school } & \multicolumn{6}{|c|}{ Tend to Disagree $\%<------------\rightarrow$ Tend to Agree $\%$} \\
\hline & SD & MD & $\mathrm{D}$ & $\mathrm{A}$ & MA & SA \\
\hline & 4.5 & 11.2 & 20.3 & 37.6 & 20.8 & 5.6 \\
\hline & \multicolumn{3}{|c|}{$36 \%$} & \multicolumn{3}{|c|}{$64 \%$} \\
\hline \multirow[t]{2}{*}{ I know my school's mission and vision well } & 11.6 & 23.4 & 26.4 & 30.5 & 6.1 & 2.0 \\
\hline & \multicolumn{3}{|c|}{$61.4 \%$} & \multicolumn{3}{|c|}{$38.6 \%$} \\
\hline \multirow[t]{2}{*}{ My school is profit oriented } & 6.1 & 6.1 & 19.9 & 36.2 & 18.9 & 12.8 \\
\hline & \multicolumn{3}{|c|}{$32.1 \%$} & \multicolumn{3}{|c|}{67.9} \\
\hline \multirow[t]{2}{*}{ My school cares a lot about reputation and image } & 0.5 & 0.0 & 12.3 & 34.9 & 31.8 & 20.5 \\
\hline & \multicolumn{3}{|c|}{$12.8 \%$} & \multicolumn{3}{|c|}{$87.2 \%$} \\
\hline \multirow{2}{*}{$\begin{array}{l}\text { I am well rewarded for my non-academic achievements } \\
\text { in school }\end{array}$} & 9.1 & 11.2 & 28.4 & 33.0 & 15.3 & 3.0 \\
\hline & \multicolumn{3}{|c|}{$48.7 \%$} & \multicolumn{3}{|c|}{$51.3 \%$} \\
\hline
\end{tabular}

On a separate note, a question was posed to determine if the forms of incentives provided in schools are sufficient, and the replies show a large percentage $48.7 \%$ students tend to disagree. This implies that schools need to get back to the drawing board, rethink and improve their incentives given to students for their non-academic achievements.

\subsection{Type and quality of information}

When it comes to the type and quality of information, a sample list of criteria was given to the respondents (Table 3). In general, students are highly agreeable with regards to the need of information to contain characteristics such as credibility (90 per cent), accuracy (88.9 per cent) and ease of understanding (86.4 per cent). A separate set of questions found that students do indeed follow through (75.5 per cent) and evaluate the information that they receive.

\subsection{Competition}

From Table 4, statements that focused on the environment revealed students are studying in an extremely competitive environment (85.5 per cent). A noticeable lesser amount of students agreed that the competition in their school is healthy (64.6 per cent), and an even lesser amount stated that the resulting stress is healthy (56.6 percent).

Overall, this reaffirms the fact that competition is still one of the dominating factors that affects knowledge sharing.

Table 2: Information quality

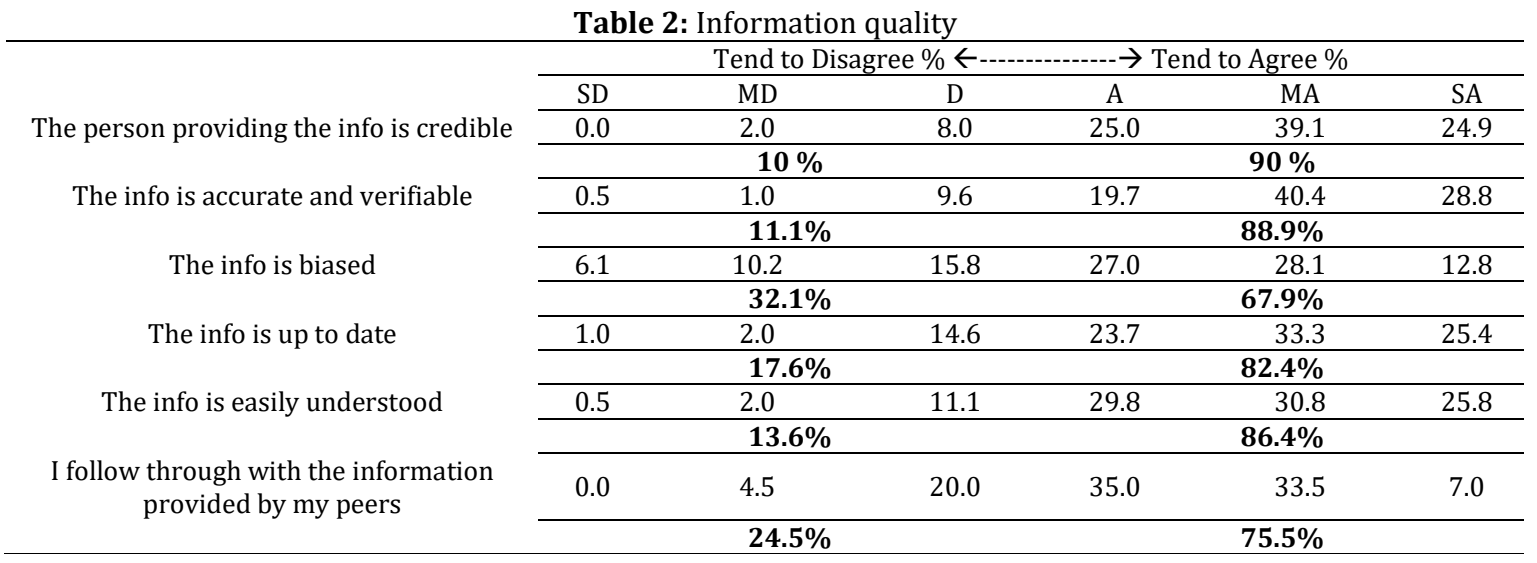

\subsection{Wikipedia}

The concept of having a school-based knowledge sharing system akin to that of Wikipedia was mentioned in the questionnaire. From Table 5, the responses were highly favourable - 87.3 per cent liked the concept and 85.3 per cent would think when it comes to whether or not they would be willing to contribute to the school based knowledge sharing system, the figures dipped to 78 per cent. A lesser amount of people are willing to share information but more are looking forward to receive information that it is feasible idea.

\section{Conclusion}

When asked if the students know of knowledge sharing systems that are in place that facilitates their study in their school, and about $50 \%$ of them replied that they do indeed have such a system. When requested to provide the names of such systems, a sizeable amount provided relevant responses such as iVLE (integrated virtual learning environment) and BlackBoard, which are online learning facilities closest to knowledge sharing, however there were also quite a few which gave responses such as "Yahoo", "Google" and "Computers". The above 
findings pointed to students' possible lack of awareness when it comes to schools' attempts to facilitate a knowledge sharing environment. Perhaps more effort is needed from institutions to share their knowledge hubs with students, more promotions would help to create greater awareness among students.

Table 3: Competition among students

\begin{tabular}{|c|c|c|c|c|c|c|}
\hline \multirow[b]{3}{*}{ I study in an extremely competitive environment } & \multicolumn{6}{|c|}{ Tend to Disagree $\%<------------\rightarrow$ Tend to Agree $\%$} \\
\hline & SD & MD & $\mathrm{D}$ & A & MA & SA \\
\hline & 0.5 & 1.5 & 12.5 & 31.0 & 34.5 & 20.0 \\
\hline \multirow{3}{*}{$\begin{array}{l}\text { I think the stress encountered in school is at a healthy } \\
\text { level }\end{array}$} & \multicolumn{3}{|c|}{$14.5 \%$} & \multicolumn{3}{|c|}{$85.5 \%$} \\
\hline & 9.1 & 11.6 & 22.7 & 36.9 & 14.1 & 5.6 \\
\hline & \multicolumn{3}{|c|}{$43.4 \%$} & \multicolumn{3}{|c|}{$56.6 \%$} \\
\hline \multirow[t]{2}{*}{ I think there is a healthy level of competition in school } & 3.5 & 5.1 & 26.8 & 38.4 & 21.2 & 5.0 \\
\hline & \multicolumn{3}{|c|}{$35.4 \%$} & \multicolumn{3}{|c|}{$64.6 \%$} \\
\hline \multirow{2}{*}{$\begin{array}{l}\text { I am afraid that my contribution to others will place } \\
\text { me in a disadvantageous position }\end{array}$} & 8.5 & 15.5 & 25.0 & 28.5 & 14.0 & 8.5 \\
\hline & \multicolumn{3}{|c|}{$49.0 \%$} & \multicolumn{3}{|c|}{$\mathbf{5 1 \%}$} \\
\hline \multirow[t]{2}{*}{ I avoid giving a complete answer to my peers } & 16.7 & 20.7 & 22.2 & 25.3 & 11.1 & 4.0 \\
\hline & \multicolumn{3}{|c|}{$59.6 \%$} & \multicolumn{3}{|c|}{$40.4 \%$} \\
\hline \multirow[t]{2}{*}{$\begin{array}{l}\text { I will provide the information to people whom I } \\
\text { perceive to be less of a threat to me }\end{array}$} & 13.0 & 21.5 & 18.5 & 26.0 & 15.0 & 6.0 \\
\hline & \multicolumn{3}{|c|}{$53 \%$} & \multicolumn{3}{|c|}{$47 \%$} \\
\hline
\end{tabular}

Table 4: Web-based user-generated knowledge sharing

\begin{tabular}{|c|c|c|c|c|c|c|}
\hline & \multicolumn{6}{|c|}{ Tend to Disagree $\%<------------\rightarrow$ Tend to Agree $\%$} \\
\hline \multirow{3}{*}{ I like the concept of Wikipedia } & SD & MD & $\mathrm{D}$ & A & MA & SA \\
\hline & 1.0 & 3.6 & 8.1 & 26.4 & 26.9 & 34.0 \\
\hline & \multicolumn{3}{|c|}{$12.7 \%$} & \multicolumn{3}{|c|}{$\mathbf{8 7 . 3 \%}$} \\
\hline \multirow{2}{*}{$\begin{array}{l}\text { I would think a school based } \\
\text { knowledge sharing portal is feasible }\end{array}$} & 0.5 & 2.0 & 12.2 & 25.4 & 32.0 & 27.9 \\
\hline & \multicolumn{3}{|c|}{$14.7 \%$} & \multicolumn{3}{|c|}{$85.3 \%$} \\
\hline \multirow{2}{*}{$\begin{array}{l}\text { I would be willing to contribute to the } \\
\text { school based knowledge sharing portal }\end{array}$} & 2.0 & 4.6 & 15.4 & 36.9 & 18.5 & 22.6 \\
\hline & \multicolumn{3}{|c|}{$22.0 \%$} & \multicolumn{3}{|c|}{$78.0 \%$} \\
\hline
\end{tabular}

In conclusion, students are found aware of the benefits of knowledge sharing and Singapore student have the right ingredient for knowledge sharing such as being social and working well in groups. They know the importance of well-evaluated information without using information received blindly. The conditions required for knowledge sharing are lacking in schools hence limiting knowledge sharing activities. This can be inferred from the lack of proper alignment between schools and students. Students perceive schools to be profit-oriented though this may not be the image that the schools would want to project. A further limiting factor is the competition that is highly prevalent in institutions in Singapore. The level of competition discourages highly competitive students from exchanging knowledge with others.

\section{Limitations and future study}

The respondents in this study were from various faculties in the education institutes. Students from certain faculties / institutions lacked information on knowledge management as their institutions are yet to make investment in knowledge management / knowledge sharing systems. Certain questions had a degree of ambiguity in it, which may have led to some anomalous results. For example, when given the statement "The info is biased" some respondents interpreted it to be implying that biasness of information counts while others thought that the info given out is bias. Such ambiguity could be reduced in future studies to ensure responses are more cohesive.

Singapore is a melting pot of students from all over the globe hence personality attributes could differ greatly between students from the same education institution. This blurring of the lines makes it difficult to get a more original view on the differences in attitudes and personality of students in private and public education institutes. Future studies' focus could be more on the comparison between the differing attitudes of private and public education institutes. They could also emphasis researching outside the ASEAN context to allow for a wider spectrum of views to converge and conclude the different methods suitable for applying knowledge sharing systems in different cultures and regions.

\section{References}

Behery MH (2008). Leadership, knowledge sharing, and organizational benefits within the UAE. Journal of American Academy of Business, 12(2): 227-237.

Bennet D and Bennet A (2008). The depth of knowledge: Surface, shallow or deep?. Vine: The Journal of Information and Knowledge Management Systems, 38(4): 405-420.

Bloom BS (1956). Taxonomy of educational objectives: The classification of educational goals. Longman, London, UK.

Crovitz D and Smoot WS (2009). Wikipedia: Friend, not foe. English Journal, 98 (3): 91-97. 
Davenport TH and Prusak L (1998). Working knowledge: How organizations manage what they know. Harvard Business Press, Boston, USA.

Desouza KC and Raider JJ (2006). Cutting corners: CKOs and knowledge management. Business Process Management Journal, 12(2): 129-134.

Dewey J (1938), Experience and education, The Macmillan Company, New York. USA.

Fitzgerald MA (2000). Critical thinking 101: The basics of evaluating information. Knowledge Quest, 29(2): 13-20.

French JRP and Raven B (2015). The bases of social power. In: Shafritz JM, Ott JS, and Jang YS (Eds.), Classics of Organization Theory: 251-283. Cengage Learning, Boston, USA.

Grant RM (1996). Toward a knowledge based theory of the firm. Strategic Management Journal, 17(S2): 109-22.

Jarvenpaa SL and Staples DS (2001). Exploring perceptions of organizational ownership of information and expertise. Journal of Management Information Systems, 18(1): 151-83.

Laycock M (2005). Collaborating to compete: achieving effective knowledge sharing in organizations. The Learning Organisation, 12(6): 523-538.

Lin CP (2007). To share or not to share: modelling knowledge sharing using exchange ideology as a moderator. Personnel Review, 36(3): 457-475.

Marouf LN (2007). Social networks and knowledge sharing in organizations: A case study. Journal of Knowledge Management, 11(6): 110-125.
MOF (2009). The Revenue and Expenditure Estimates for the Financial Year 2009/2010. Ministry of Finance, Singapore.

Mooradian T, Renzl B, and Matzler K (2006). Who trusts? personality, trust and knowledge sharing. Management Learning, 37(4): 523-540.

Nonaka I (1994). A dynamic theory of organizational knowledge creation. Organizational Science, 5(1): 14-37.

Nonaka I and Takeuchi H (1995). The knowledge-creating company: How Japanese companies create the dynamics of innovation. Oxford University Press, Oxford, UK.

Politi JD (2005). The influence of managerial power and credibility on knowledge acquisition attributes. Leadership and Organization Development Journal, 26(3): 197-214.

Rahman MM (2008). An analysis of Wikipedia. JITTA Journal of Information Theory and Application, 9(3): 81-98.

Senge P (1990). The fifth discipline. Doubleday, New York, USA.

Senge P (1998). Sharing knowledge: You can't own knowledge, so why not share it?. Executive Excellence, 15: 11-12.

Ting JY and Majid MS (2007). Knowledge-sharing patterns of undergraduate students in Singapore. Library Review, 56(6): 485-494.

Wolfe C and Loraas T (2008). Knowledge sharing: The effects of incentives, environment, and person. Journal of Information Systems, 22(2): 53-76.

Yi J (2006). Externalization of Tacit Knowledge in Online Environments. International Journal on E-Learning, 5(4): 663674. 